Bond University

Research Repository

\title{
A profile of health, lifestyle and training habits of 4720 Australian recreational runners-The case for promoting running for health benefits
}

Kozlovskaia, Maria; Vlahovich, Nicole; Rathbone, Evelyne; Manzanero, Silvia; Keogh, Justin; Hughes, David C.

Published in:

Health Promotion Journal of Australia

DOI:

10.1002/hpja.30

Licence:

Unspecified

Link to output in Bond University research repository.

Recommended citation(APA):

Kozlovskaia, M., Vlahovich, N., Rathbone, E., Manzanero, S., Keogh, J., \& Hughes, D. C. (2019). A profile of health, lifestyle and training habits of 4720 Australian recreational runners-The case for promoting running for health benefits. Health Promotion Journal of Australia, 30(2), 172-179. https://doi.org/10.1002/hpja.30

\section{General rights}

Copyright and moral rights for the publications made accessible in the public portal are retained by the authors and/or other copyright owners and it is a condition of accessing publications that users recognise and abide by the legal requirements associated with these rights.

For more information, or if you believe that this document breaches copyright, please contact the Bond University research repository coordinator 
Significant weight loss and health benefits associated with running: a cross-sectional study of 4720

\section{Australian recreational runners.}

Ms Maria Kozlovskaia ${ }^{1,2}$, Dr Nicole Vlahovich², Ms Evelyne Rathbone², Dr Silvia Manzanero², Dr Justin Keogh $^{1}$, Dr David C. Hughes ${ }^{2}$.

1. Bond University, Faculty of Health Sciences and Medicine, 14 University Drive, Robina, QLD 4226

2. Australian Institute of Sport, Department of Sports Medicine, 1 Leverrier Street, Bruce, ACT 2617 


\section{A profile of health and training habits of Australian recreational runners - the case for promoting recreational running for health benefits.}

\section{Abstract}

Issue addressed: The aim of the study was to characterise lifestyle and training habits of a large cohort of Australian recreational runners. Understanding the health benefits of recreational running and differentiating between the habits of males and females may allow for the development of gender specific messaging for promoting recreational running as a form of physical activity.

Methods: An online questionnaire was used to collect data from 4720 Australian recreational runners. Data on physical, lifestyle and training characteristics of male and female subgroups were compared using Chi-square tests. Multiple logistic regression method was used to assess the effect of running experience on the reported clinically significant weight loss.

Results: The study cohort was $54.1 \%$ female and $45.9 \%$ male. The majority $(72.9 \%)$ of runners had normal BMI and the cohort had significantly lower overweight/obesity rate than the Australian population. The logistic regression model indicated that commencing running may lead to a clinically significant weight loss irrespectively of sex, participation in other sports and injury history. Smoking was uncommon among surveyed runners. The most typical weekly running distance in the cohort was 20-40 km, usually distributed by 2-5 running sessions. Significantly more males than females reported running over $40 \mathrm{~km}$ per week and running more sessions.

Conclusion: Recreational running was associated with beneficial health outcomes. Commencement of running is associated with weight loss and regular running supports healthy weight maintenance. Male and female runners had different running preferences which should be taken into account for physical activity promotion.

Key words: Running, Running habits, Weight loss, Health, Body mass index 



\section{Introduction}

According to the World Health Organisation (WHO) the leading global risk factors for mortality are hypertension (responsible for $13 \%$ of deaths globally), tobacco use (9\%), hyperglycaemia (6\%), physical inactivity (6\%), and overweight and obesity (5\%).(1) Approximately $31 \%$ of the burden of disease in Australia could be prevented by reducing exposure to modifiable risk factors such as tobacco use, harmful alcohol use, high body mass, physical inactivity and hypertension.(2) Clinically significant weight loss of $\geq 5 \mathrm{~kg}$ or $5 \%$ of baseline body weight was shown to be associated with health benefits and reduced risks of cardiovascular disease, type 2 diabetes mellitus and hypertension.(3-5) Health benefits of physical activity include decreased risks of chronic conditions including type 2 diabetes mellitus, cardiovascular disease and depression. Physical inactivity causes $6-10 \%$ of the burden of disease worldwide and $9 \%$ of premature mortality.(6-8) Promotion of physical activity by general practitioners could help to address this issue, however, only one-fifth of Australians reported receiving such recommendations, suggesting that strategies to encourage exercise prescription by a variety of health professionals require consideration.(9)

The WHO Physical Activity Guidelines recommend 150 minutes of moderate-intensity aerobic physical activity or 75 minutes of vigorous-intensity physical activity throughout the week, based on strong evidence of health benefits and reductions upon mortality rates.(10) However, according to the report from the National Health Survey conducted in $2014-2015$, only $57.7 \%$ of Australian men and $53.3 \%$ of Australian women met the WHO Physical Activity Guidelines.(11) Recreational running, which may also be referred to as jogging, is one of the most common physical activities worldwide, with regular running consistently shown to reduce all-cause and cardiovascular mortality risks.(12-16) In Australia, the rate of participation in running increased from $4.3 \%$ in $2005-06$, to $7.4 \%$ in $2013-14 .(17)$ Recent data have indicated that current participation levels in athletics, including running, in the Australian population may be as high as $15.8 \%$.(18) Running provides a low-cost option for increasing physical activity, without the restrictions of specific equipment or costs of sports club membership. Furthering the understanding of the running habits and wider health characteristics of male and female 
recreational runners may assist in the development of sex specific messaging to promote the health benefits of recreational running as a form of physical activity.

The aim of this study was firstly, to describe the health and lifestyle characteristics of Australian recreational runners and compare body mass index (BMI) to the Australian general population, and secondly to examine the similarities and differences in training habits of male and female runners. It was hypothesised that recreational runners would display characteristics of a healthy lifestyle including participation in physical activity, maintaining a healthy BMI and having low rates of chronic disease and smoking.

\section{Methods}

\subsection{Study design}

The Australian Institute of Sport (AIS) Running Injury Study was a cross-sectional retrospective study of self-described recreational runners. Participants were self-selected for inclusion into the study with inclusion criteria being age over 18 years and recreational running practice of more than $15 \mathrm{~km}$ per week. This self-reported, retrospective questionnaire, delivered using Internet software (SurveyGizmo), was previously demonstrated to provide stable and reliable data.(19) This survey contained questions covering demographic characteristics, running habits, injury history (e.g. injured/uninjured in prior two years and details about particular injuries), dietary habits (e.g. nutritional requirements and dietary supplements), and female health (for female participants e.g. menstrual cycle), The full questionnaire tool was published by Domaschenz et al.(19) Data relating to dietary habits and female health were not related to the current hypothesis and are not reported here. The study was approved by the Bond University Human Research Ethics Committee (approval RO1688B).

\subsection{Data Collection}

Study participants in the AIS Running Injury Study were recruited through social media, at running events, and via promotion through a range of online websites and traditional media sources. The enrolment period spanned September 2014 until October 2016. All respondents provided informed 
consent to participate and provided personal data after accepting the conditions of the study on the first page of the online questionnaire.

Participants' BMI was calculated from the responses to weight $(\mathrm{kg})$ and height $(\mathrm{cm})$ and categorised as underweight $\left(16-18.5 \mathrm{~kg} / \mathrm{m}^{2}\right)$, normal $\left(18.5\right.$ to $\left.<25 \mathrm{~kg} / \mathrm{m}^{2}\right)$, overweight $\left(25\right.$ to $\left.<30 \mathrm{~kg} / \mathrm{m}^{2}\right)$, category I of obesity (30 to $\left.<35 \mathrm{~kg} / \mathrm{m}^{2}\right)$, category II of obesity $\left(35\right.$ to $<40 \mathrm{~kg} / \mathrm{m}^{2}$ ) and category III of obesity ( $\geq 40$ $\left.\mathrm{kg} / \mathrm{m}^{2}\right)$.

\subsection{Statistical Analyses}

Statistical analysis was conducted in IBM SPSS Statistics version 24 (SPSS, Inc.). All numerical variables were checked for normality using Kolmogorov-Smirnov and Q-Q plots, which indicated that the data were not normally distributed. Median, minimum and maximum values and interquartile range (IQR) were calculated for physical characteristics (age, height, weight, BMI) and independently presented for the entire cohort and male and female subgroups. Mann-Whitney $U$ test was performed to compare the distributions of these continuous variables between male and female subgroups and showed a significant difference $(p<0.001)$ across all four variables. There were no missing data for these variables. Logarithmic transformation was attempted to correct skewness, however, the majority of the variables remained skewed after the transformation. Therefore, BMI and age were categorised and subsequent analyses were performed using only categorical variables.

Categorical variables describing running habits and health conditions were summarised using counts and percentages. Male and female subgroups were compared for all categorical variables using Chisquare test. Not available (NA) data were presented for each categorical variable and comprised less than $0.5 \%$. BMI data of recreational runners were compared to published health data from the Australian general population (18-74 years of age) which had been collected in the same way.

Multiple logistic regression was performed to assess the effect of running experience on the reported clinically significant weight loss ( $\geq 5 \mathrm{~kg}$ ), after adjusting for sex, age, BMI, participation in other sports, smoking history and injury history. Whilst weekly running distance and race pace were both independently strongly associated $(p<0.001)$ with reported weight loss in univariable analyses, they 
were not used as predictors in the model due to strong association with running experience and sex respectively. To avoid multicollinearity, only predictors of interest that were not strongly associated with each other were selected in the model. Results of the multivariable analysis are presented as adjusted odds ratios with $95 \%$ confidence intervals and $p$-values. A Hosmer and Lemeshow test indicated that the model fit was acceptable $\left(\chi_{8}^{2}=11.69, p=0.17\right)$. Statistical significance was set at $p<0.05$

\section{Results}

Data from 5250 respondents who described themselves as recreational runners were collected over the 25-month period of recruitment. After duplicate $(n=272)$, nonsense $(n=4)$ and incomplete $(n=35)$ responses were removed, 4939 responses remained. As a weekly running distance of greater than 15 $\mathrm{km}$ was stated as an inclusion criterion for participation in the survey, data from 219 runners who reported less than this distance were removed, resulting in 4720 responses included in the analysis. All respondents were 18 years of age or over. The study cohort was $54.1 \%$ female and $45.9 \%$ male (Table 1). A summary of training characteristics is displayed in Table 2. Frequencies of the reported lifetime chronic conditions are shown in Table 3. Summary statistics for BMI groups and logistic regression analysis of clinically significant weight loss are displayed in Tables 4 and 5.

\subsection{Running habits}

The training characteristics of respondents are described in Table 2 . The most common weekly running distance was $20-40 \mathrm{~km}(45.8 \%)$ among the entire cohort, with very similar rates in male and female runners. However, males were more likely than females to run distances more than $40 \mathrm{~km}$ per week $\left(\chi_{1}^{2}=77.6, p<0.001\right)$, whereas females were more likely than males to run less than $20 \mathrm{~km}$ per week $\left(\chi_{1}^{2}=65.5, p<0.001\right)$. The most common category of respondents were those with over ten years of running experience (37.8\%), with significantly more males than females within this experienced group $\left(\chi_{1}^{2}=71.3, p<0.001\right)$. The majority of respondents stated that they typically ran between two and five sessions per week. It was however observed that males were significantly more likely to run six or more times per week than females $\left(\chi_{1}^{2}=33.3, p<0.001\right)$. The typical race pace of a male runner was 
reported as 4-5 $\mathrm{min} / \mathrm{km}$, whereas female runners reported 5-6 $\mathrm{min} / \mathrm{km}$. The majority of respondents participated in other sports in addition to running. Significantly more female than male runners reported participation in sports other than running $\left(\chi_{1}^{2}=63.8, p<0.001\right)$. Almost a half of recreational runners reported injuries that occurred while running in the past two years, with significantly higher rates in males than in females $\left(\chi_{1}^{2}=7.7, p=0.003\right)$.

\subsection{Smoking habits}

Smoking was uncommon among surveyed runners, with $0.6 \%$ reporting that they were current smokers and a further $25.8 \%$ of runners reporting that they had smoked at any time in their life. Reported smoking experience was not significantly associated with sex $\left(24.7 \%\right.$ versus $26.7 \% ; \chi_{1}^{2}=2.1$, $p=0.1)$.

\subsection{Chronic conditions}

The survey included questions about 18 lifetime diagnoses of chronic conditions (Table 3). The most common reported diagnosis was depression (15.3\%) with significantly higher reported depression rates among females than males $\left(18.9 \%\right.$ versus $\left.11.1 \% ; \chi_{1}^{2}=55.7, p<0.001\right)$. The second most common diagnosis was respiratory conditions $(11.7 \%)$, which was significantly higher in females than males (13\% versus $\left.10.2 \% ; \chi_{1}^{2}=9.0, p=0.002\right)$. Although anaemia was the third most common diagnosis $(10 \%)$, this was mainly reported by females $\left(17.1 \%\right.$ versus $\left.1.6 \%, \chi_{1}^{2}=315.8, p<0.001\right)$. A lifetime diagnosis of hypertension was reported by 290 runners (6.1\%). Hypertension was the third most common diagnosis for males, accounting for $7.8 \%$, with a significantly lower reported rate in females $-4.8 \%$ $\left(\chi_{1}^{2}=18.1, p<0.001\right)$.

\subsection{Body mass index and weight loss}

Respondents were grouped by their BMI in accordance with the World Health Organisation guidelines (Table 4).(20) The majority of runners were in the normal weight category with a BMI between 18.5 $\mathrm{kg} / \mathrm{m}^{2}$ and $25 \mathrm{~kg} / \mathrm{m}^{2}$ (72.9\%). Of the remainder, $2.6 \%$ of runners were underweight (16 to $18.5 \mathrm{~kg} / \mathrm{m}^{2}$ ), $21.8 \%$ were overweight $\left(25\right.$ to $\left.<30 \mathrm{~kg} / \mathrm{m}^{2}\right)$ and $2.7 \%$ were obese $\left(\geq 30 \mathrm{~kg} / \mathrm{m}^{2}\right)$. There were no participants in the cohort that were classified as severely underweight $\left(<16 \mathrm{~kg} / \mathrm{m}^{2}\right)$. When levels of 
obesity were categorised, 127 runners were divided into 3 subgroups: category I of obesity $(n=111)$, category II $(n=14)$ and category III ( $n=2)$, accounting for approximately $2.35 \%, 0.30 \%$ and $0.04 \%$ respectively of the entire sample. Due to these low numbers in severe and very severe categories, it was decided to keep a general 'obese' group for analysis. Significantly more women than men were in the underweight and normal weight categories $\left(\chi_{1}^{2}=50.6, p<0.001 ; \chi_{1}^{2}=66.8, p<0.001\right.$ respectively), whereas significantly more men than women were overweight $\left(\chi_{1}^{2}=136.3, p<0.001\right)$. Nevertheless, proportions of obese male and female runners were almost equal. The BMI distribution data of surveyed runners were compared to BMI data in the Australian population collected in the 2014-15 National Health Survey published by the Australian Bureau of Statistics (ABS) (Figure 1).(11)

Recreational runners were asked whether they had gained or lost a clinically significant amount of weight $(\geq 5 \mathrm{~kg})$ in the past two years. Clinically significant weight loss over the last two years was reported by $27 \%$ of all respondents. Multiple logistic regression analysis (Table 5 ) showed that clinically significant weight loss was more likely to be reported by younger runners, and overweight and obese runners. Runners with two or less years of running experience were three times more likely to report clinically significant weight loss in the past two years than runners with over ten years of running experience. However, sex, participation in other sports, and history of injuries in the past two years did not have a statistically significant association with clinically significant weight loss. Interestingly, smoking experience (smoking at any time in life) was associated with reported clinically significant weight loss. The logistic regression results indicate that commencing a running program may lead to a clinically significant weight loss irrespective of sex, participation in other sports and injury in the previous two years.

\section{Discussion}

This study described one of the largest cohorts of recreational runners, analysing the medical and lifestyle characteristics of the participants and sex differences in training habits. In this study, we demonstrated that a large proportion of recreational runners avoided the majority of modifiable risk factors that contribute to the burden of disease. In the Australian population, the five strongest 
contributors to the burden of disease in 2011 were tobacco use (9\%), high body mass (5.5\%), alcohol use (5\%), physical inactivity (5\%) and hypertension (5\%).(21) Data from the Australian Nutrition and Physical Activity Survey showed that both sufficient physical activity level and reduced sitting time were important factors for prevention of cardiovascular disease and metabolic syndrome.(22) This study demonstrated that Australian recreational runners typically have a BMI in the normal range, are meeting physical activity guidelines through recreational running and participation in other sports, and have low levels of smoking. This cohort runs on average $20-40 \mathrm{~km}$ in greater than two sessions per week, and $76.1 \%$ of respondents play additional sport, indicating that recreational runners are likely to be meeting the recommended WHO Physical Activity Guidelines. Considering that $80 \%$ of surveyed recreational runners have been running for at least three years, we can speculate that they have managed to sustain a habit of regular physical activity at the recommended level for at least three years.

Australian recreational runners self-reported a lower BMI than the general population. Additionally, a weight loss of greater than five kilograms in the past two years was reported by approximately $40 \%$ of runners with less than two years of experience. Physical activity is a key component in the multidisciplinary approach of effective weight loss programs, and is especially important when preventing continued weight gain or maintaining lower weight.(23) Indeed, endurance running has been shown to be beneficial to physically inactive adults leading to body mass and body fat reduction, with a systematic review concluding that one year of running training was effective in reducing body mass by $3.3 \mathrm{~kg}$.(24) Several systematic reviews have shown that aerobic exercise, such as running, significantly contributes to weight loss, with strong evidence that this type of activity is effective in reducing visceral fat.(25, 26) Additionally there is a dose-response relationship between aerobic exercise and visceral fat reduction in obese participants, indicating that an activity such as recreational running could be effective in improving health via a reduction of visceral fat.(27) A systematic review indicated that risks of all-cause mortality and cardiovascular mortality were lower in people with high $\mathrm{BMI}$ and good aerobic fitness than in people with normal BMI and poor fitness. However, aerobically 
fit people with high BMI were still at a greater risk of type 2 diabetes mellitus and cardiovascular disease.(28) In an Australian population it has been shown that walking is the most common type of physically activity recommended to patients by their doctor. $(29,30)$ Our results, taken together with previous findings indicate that recreational running could be promoted by general practitioners as an effective mechanism for building aerobic fitness and maintaining a healthy body weight.

Only one quarter of recreational runners surveyed reported smoking at any time during their life and $0.6 \%$ were current smokers. These rates were substantially lower than those reported by the Australian Bureau of Statistics, which showed that $14.5 \%$ of adult Australians were daily smokers, $1.5 \%$ smoked less often than daily and about one third (31.4\%) were ex-smokers.(11) A systematic review of co-occurrence of smoking and physical activity showed negative association in 20 studies on adults in several European countries, Japan and Australia and 13 studies with nonsignificant, mixed or positive association, indicating possible complex relationships between smoking and physical activity due to race, income level and other factors.(31) Hence, the very small proportion of runners currently smoking could reflect their overall healthy lifestyle as well as the positive effects of individual exercise bouts in reducing cravings for smoking.

Depression was the most common life-time diagnosis reported by recreational runners (15.3\%). Affective disorders, which comprise all levels and severity of depressive disorders and bipolar disorder, accounted for $15 \%$ of life-time prevalence in Australian population.(32) The depression prevalence in the Australian recreational running population is largely the same as in the general population. Hypertension is a significant risk factor for chronic diseases including stroke, coronary heart disease, heart failure and chronic kidney disease and is identified as the leading global risk factor for mortality.(1) Based on measured data from the Australian Institute of Health and Welfare, $32 \%$ of Australians aged 18 and over have hypertension.(33) However, only 6.1\% of Australian recreational runners surveyed self-reported that they had been diagnosed with hypertension. The reduced levels suggest that recreational running is associated with lower rates of hypertension as a risk factor for burden of disease. 
Running, as a form of physical activity, has consistently been shown to provide a range of health benefits, including reducing the overall risk of cardiovascular disease and all-cause mortality.(12, 13, $15,34)$ More importantly, the clustering of various healthy behaviours has been shown to be inversely related to the risk of all-cause mortality, with four or more healthy behaviours reducing mortality risk by $66 \%$.(35) Here we demonstrated that a large proportion of Australian recreational runners displayed healthy behaviours including meeting physical activity guidelines, avoidance of overweight or obesity and reduced smoking.

We suggest that recreational running could be promoted as a low-cost option for adhering to physical activity guidelines. Marketing of recreational running through mass participation events, for example parkrun, has been considered as a public health intervention. $(36,37)$ However, there is a risk of sustaining an injury during participation in recreational running, with $49 \%$ of participants in this study reporting a running injury over the preceding two years. This potential injury risk must be taken into account when advising participation in recreational running. Additionally, commencement of a running program for individuals with musculoskeletal injuries of the lower body should be supervised by a qualified medical practitioner. The current study demonstrated that there are differences in male and female preferences to consider when aiming to encourage people to begin a running program. We show here that female runners were more likely to report shorter weekly distances while running a similar number of sessions as male runners. This study did not investigate the motivations for participation in recreational running, however several studies have demonstrated that the motivations of males and females, in relation to participation in physical activity, differ in a number of ways.(38-40) An Australian study demonstrated that, while both males and females are motivated by general health and maintenance of fitness, women often cite weight loss/appearance and mental health as motivating factors for increasing their physical activity levels while men participate for social reasons and enjoyment.(18) Both motivational factors and running habits should be taken into account when marketing recreational running for health benefits or encouraging participation. 
While the self-report nature of data collection could introduce bias and error, the survey tool has been shown to be reliable and questions did not require respondents to recall long-term details of running habits or injuries. (19) The term of recall for injuries and running habits was limited to the two years preceding survey response, as it has been show that retrospective data beyond this point is not reliable. $(41,42)$ A further study limitation may have been sampling bias with higher proportion of female runners and middle-aged runners in the studied cohort in comparison with a demographic data of physically active Australian adults.(17) Lastly, absence of data from non-runners or those who may be interested in taking up recreational running precludes extrapolation of findings to nonrunners.

\section{Conclusion}

Recreational running is associated with benefits across a range of measurable health outcomes. A high proportion of the Australian recreational runners who participated in this study had a body mass index within the healthy weight range, seemed to be meeting the WHO Physical Activity Guidelines each week for many years and were non-smokers. Additionally, our results indicate that taking up running is associated with weight loss and weight remains stable if individuals persist with running. Male and female runners reported different running preferences and these should be taken into account when promoting recreational running or encouraging participation.

\section{Acknowledgements}

The authors thank Dr Renae Domaschenz and Prof Maria Fiatarone-Singh for their contribution to the development of the questionnaire used in this study. Associate Professor Kevin Ashton and Dr Paul Leo are acknowledged in for their roles as supervisors of MK. The authors also thank the Collaborative Research Network for Advancing Exercise and Sports Science Scientific Committee members who contributed to this work: Professor Nuala Byrne (Bond University), Professor Matthew A Brown (Queensland University of Technology) and Professor Maria A. Fiatarone-Singh (University of Sydney).

\section{Authors' contributions}



MK participated in the study design, data collection, performed data analysis and drafted the manuscript; NV participated in the study design, data collection, helped to draft the manuscript; ER helped with data analysis and revised the draft of the manuscript; SM participated in the data collection and revised the draft of the manuscript; JK participated in the study design and data collection and revised the draft of the manuscript. DCH participated in the study design, helped to draft the manuscript and then revised the draft of the manuscript. All authors read and approved final version of the paper and agreed with the order of presentation of 266 the authors.

267 None of the authors declare competing financial interests. Funding Source

269 This work was supported by the Collaborative Research Network for Advancing Exercise and Sports Science (CRN-AESS; MK, NV, JK, SM and DCH). 
1.World Health Organization. Global health risks: mortality and burden of disease attributable to selected major risks: World Health Organization; 2009.

2.Australian Institute of Health and Welfare. Australia's health 2016. In: AlHW, editor. Canberra 2016. 3.Neter JE, Stam BE, Kok FJ, Grobbee DE, Geleijnse JM. Influence of weight reduction on blood pressure. Hypertension. 2003;42(5):878-84. 4.Diabetes Prevention Program Research Group. Reduction in the incidence of type 2 diabetes with lifestyle intervention or metformin. N Engl j Med. 2002;2002(346):393-403.

5.Look AHEAD Research Group. Long term effects of a lifestyle intervention on weight and cardiovascular risk factors in individuals with type 2 diabetes: four year results of the Look AHEAD trial. Archives of internal medicine. 2010;170(17):1566.

6.Physical Activity Guidelines Advisory Committee. Physical activity guidelines advisory committee report, 2008. Washington, DC: US Department of Health and Human Services. 2008;2008:A1-H14.

7.Lee I-M, Shiroma EJ, Lobelo F, Puska P, Blair SN, Katzmarzyk PT, et al. Effect of physical inactivity on major non-communicable diseases worldwide: an analysis of burden of disease and life expectancy. The lancet. 2012;380(9838):219-29.

8.Reiner M, Niermann C, Jekauc D, Woll A. Long-term health benefits of physical activity-a systematic review of longitudinal studies. BMC public health. 2013;13(1):813.

9.Short CE, Hayman M, Rebar AL, Gunn KM, De Cocker K, Duncan MJ, et al. Physical activity recommendations from general practitioners in Australia. Results from a national survey. Australian and New Zealand journal of public health. 2016;40(1):83-90.

10.World Health Organisation. Global recommendations on physical activity for health. 2010. 11.Australian Bureau of Statistics. National Health Survey. First results. Australia 2014-15. 2016. 12.Lee DC, Pate RR, Lavie CJ, Sui X, Church TS, Blair SN. Leisure-time running reduces all-cause and cardiovascular mortality risk. Journal of the American College of Cardiology. 2014;64(5):472-81. 13.Oja P, Kelly P, Pedisic Z, Titze S, Bauman A, Foster C, et al. Associations of specific types of sports and exercise with all-cause and cardiovascular-disease mortality: a cohort study of 80306 British adults. British Journal of Sports Medicine. 2016:bjsports-2016-096822.

14.Lee DC, Lavie CJ, Vedanthan R. Optimal Dose of Running for Longevity. Journal of the American College of Cardiology. 2015;65(5):420.

15.Schnohr P, O'Keefe JH, Marott JL, Lange P, Jensen GB. Dose of jogging and long-term mortality: the Copenhagen City Heart Study. Journal of the American College of Cardiology. 2015;65(5):411-9.

16. Hulteen RM, Smith JJ, Morgan PJ, Barnett LM, Hallal PC, Colyvas K, et al. Global participation in sport and leisure-time physical activities: A systematic review and meta-analysis. Preventive medicine. 2017;95:14-25.

17.Australian Bureau of Statistics. Participation in Sport and Physical Recreation, Australia, 2013-14. In: Statistics ABo, editor. 2015.

18.Australian Sports Commission. AusPlay Participation data for the sport sector. In: Commission AS, editor. 2016.

19.Domaschenz R, Vlahovich N, Keogh J, Compton S, Hughes CD. Exercise-Induced Tendon and Bone Injury in Recreational Runners: A Test-Retest Reliability Study. JMIR Res Protoc. 2015;4(4):e117.

20.World Health Organization. Obesity: preventing and managing the global epidemic. World Health Organization; 2000.

21.Australian Institute of Health and Welfare. Australian Burden of Disease Study: impact and causes of illness and death in Australia 2011-summary report. . Australian Burden of Disease Study Series2016.

22.Engelen L, Gale J, Chau JY, Hardy LL, Mackey M, Johnson N, et al. Who is at risk of chronic disease? Associations between risk profiles of physical activity, sitting and cardio-metabolic disease in Australian adults. Australian and New Zealand Journal of Public Health. 2016. 
23.Söderlund A, Fischer A, Johansson T. Physical activity, diet and behaviour modification in the treatment of overweight and obese adults: a systematic review. Perspectives in public health. 2009;129(3):132-42.

24. Hespanhol Junior LC, Pillay JD, van Mechelen W, Verhagen E. Meta-analyses of the effects of habitual running on indices of health in physically inactive adults. Sports Medicine. 2015;45(10):145568.

25.Ismail I, Keating S, Baker M, Johnson N. A systematic review and meta-analysis of the effect of aerobic vs. resistance exercise training on visceral fat. Obesity reviews. 2012;13(1):68-91.

26.Thorogood A, Mottillo S, Shimony A, Filion KB, Joseph L, Genest J, et al. Isolated aerobic exercise and weight loss: a systematic review and meta-analysis of randomized controlled trials. The American journal of medicine. 2011;124(8):747-55.

27.Ohkawara K, Tanaka S, Miyachi M, Ishikawa-Takata K, Tabata I. A dose-response relation between aerobic exercise and visceral fat reduction: systematic review of clinical trials. International journal of obesity. 2007;31(12):1786-97.

28.Fogelholm M. Physical activity, fitness and fatness: relations to mortality, morbidity and disease risk factors. A systematic review. Obesity reviews. 2010;11(3):202-21.

29.Robertson R, Jepson R, Shepherd A, McInnes R. Recommendations by Queensland GPs to be more physically active: which patients were recommended which activities and what action they took. Australian and New Zealand journal of public health. 2011;35(6):537-42.

30.Porter S, Eccleston P, Vilshanskaya O. Moving patients towards a more active lifestyle: the GP Physical Activity Project in South Eastern Sydney Area Health Service. Health Promotion Journal of Australia. 2002;13(3):178-83.

31.Kaczynski AT, Manske SR, Mannell RC, Grewal K. Smoking and physical activity: a systematic review. American journal of health behavior. 2008;32(1):93-110.

32.Slade J, Teesson W, Burgess P. The mental health of Australians 2: report on the 2007 National Survey of Mental Health and Wellbeing. 2009.

33.Australian Institute of Health and Welfare. High blood pressure 2017 [Available from: http://www.aihw.gov.au/risk-factors/high-blood-pressure/.

34.Chakravarty EF, Hubert HB, Lingala VB, Fries JF. Reduced disability and mortality among aging runners: a 21-year longitudinal study. Archives of internal medicine. 2008;168(15):1638-46.

35. Loef $\mathrm{M}$, Walach $\mathrm{H}$. The combined effects of healthy lifestyle behaviors on all cause mortality: a systematic review and meta-analysis. Preventive medicine. 2012;55(3):163-70.

36.Stevinson C, Wiltshire G, Hickson M. Facilitating participation in health-enhancing physical activity: A qualitative study of parkrun. International journal of behavioral medicine. 2015;22(2):170-7.

37.Stevinson C, Hickson M. Exploring the public health potential of a mass community participation event. Journal of Public Health. 2013:fdt082.

38.Stults-Kolehmainen MA, Ciccolo JT, Bartholomew JB, Seifert J, Portman RS. Age and gender-related changes in exercise motivation among highly active individuals. Athletic Insight. 2013;5(1):45-63.

39.Louw A, Van Biljon A, Mugandani S. Exercise motivation and barriers among men and women of different age groups: sport psychology. African Journal for Physical Health Education, Recreation and Dance. 2012;18(Issue-4_1):759-68.

40.Lauderdale ME, Yli-Piipari S, Irwin CC, Layne TE. Gender differences regarding motivation for physical activity among college students: A self-determination approach. The Physical Educator. 2015;72(1):153-72.

41.Gabbe BJ, Finch CF, Bennell KL, Wajswelner $\mathrm{H}$. How valid is a self reported 12 month sports injury history? British journal of sports medicine. 2003;37(6):545-7.

42.Kolt GS, Kirkby RJ. Epidemiology of injury in elite and subelite female gymnasts: a comparison of retrospective and prospective findings. British Journal of Sports Medicine. 1999;33(5):312-8. 
Table 1: Characteristics of participants.

\begin{tabular}{|c|c|c|c|c|c|c|}
\hline \multirow[t]{2}{*}{ Characteristics } & \multicolumn{2}{|r|}{$\begin{array}{r}\text { All runners } \\
(N=4720)\end{array}$} & \multicolumn{2}{|c|}{$\begin{array}{r}\text { Male runners } \\
(n=2165 ; 45.9 \%)\end{array}$} & \multicolumn{2}{|c|}{$\begin{array}{l}\text { Female runners } \\
(n=2555 ; 54.1 \%)\end{array}$} \\
\hline & Median (range) & IQR & Median (range) & IQR & Median (range) & IQR \\
\hline Age (years) & $40(18-80)$ & $33-47$ & $42(18-80)$ & $34-49$ & $39(18-77)$ & $32-46$ \\
\hline Weight (kg) & $68(40-135)$ & $60-77$ & $76(45-135)$ & $70-83$ & $61(40-110)$ & $56-68$ \\
\hline Height $(\mathrm{cm})$ & $172(120-210)$ & $165-179$ & $179(152-210)$ & $175-183$ & $166(120-190)$ & $162-170$ \\
\hline Body Mass Index (BMI) $\left(\mathrm{kg} / \mathrm{m}^{2}\right)$ & $23(16-44.4)$ & $21.3-25$ & $23.8(16-40.8)$ & $22.3-25.6$ & $22.2(16.3-44.4)$ & $20.6-24.2$ \\
\hline
\end{tabular}


Table 2: Training characteristics of Australian recreational running cohort.

\begin{tabular}{|c|c|c|c|c|c|c|c|}
\hline \multirow[t]{2}{*}{ Training characteristics } & & \multicolumn{2}{|c|}{$\begin{array}{r}\text { All runners } \\
(N=4720)\end{array}$} & \multicolumn{2}{|c|}{$\begin{array}{l}\text { Male runners } \\
\qquad(N=2165)\end{array}$} & \multicolumn{2}{|c|}{$\begin{array}{r}\text { Female runners } \\
\qquad(N=2555)\end{array}$} \\
\hline & & $n$ & $\%$ & $n$ & $\%$ & $n$ & $\%$ \\
\hline \multirow[t]{3}{*}{ Weekly running distance** } & $<20 \mathrm{~km}$ & 1424 & 30.2 & 526 & 24.3 & 898 & 35.1 \\
\hline & $20-40 \mathrm{~km}$ & 2164 & 45.8 & 991 & 45.8 & 1173 & 45.9 \\
\hline & $>40 \mathrm{~km}$ & 1132 & 24.0 & 648 & 29.9 & 484 & 18.9 \\
\hline \multirow[t]{5}{*}{ Running experience** } & $\leq 2$ years & 942 & 20.0 & 364 & 16.8 & 578 & 22.6 \\
\hline & $3-5$ years & 1267 & 26.8 & 542 & 25.0 & 725 & 28.4 \\
\hline & $6-9$ years & 722 & 15.1 & 297 & 13.7 & 425 & 16.6 \\
\hline & $10+$ years & 1783 & 37.8 & 958 & 44.2 & 825 & 32.3 \\
\hline & NA & 6 & 0.1 & 4 & 0.2 & 2 & 0.1 \\
\hline \multirow[t]{5}{*}{ Run sessions per week** } & 1 & 15 & 0.3 & 10 & 0.5 & 5 & 0.2 \\
\hline & 2 or 3 & 2041 & 43.2 & 869 & 40.1 & 1172 & 45.9 \\
\hline & 4 or 5 & 2226 & 47.5 & 1027 & 47.4 & 1199 & 46.9 \\
\hline & $6+$ & 422 & 8.9 & 250 & 11.5 & 172 & 6.7 \\
\hline & NA & 16 & 0.3 & 9 & 0.4 & 7 & 0.3 \\
\hline \multirow[t]{6}{*}{ Race pace** } & $<4 \mathrm{~min} / \mathrm{km}$ & 403 & 8.5 & 329 & 15.2 & 74 & 2.9 \\
\hline & $4-5 \mathrm{~min} / \mathrm{km}$ & 1591 & 33.7 & 1022 & 47.2 & 569 & 22.3 \\
\hline & $5-6 \mathrm{~min} / \mathrm{km}$ & 1819 & 38.5 & 633 & 29.2 & 1186 & 46.4 \\
\hline & $6-7 \mathrm{~min} / \mathrm{km}$ & 706 & 15.0 & 141 & 6.5 & 565 & 22.1 \\
\hline & $>7$ min km & 189 & 4.0 & 34 & 1.6 & 155 & 6.1 \\
\hline & NA & 12 & 0.3 & 6 & 0.3 & 6 & 0.2 \\
\hline \multirow[t]{3}{*}{ Participation in other sports** } & Yes & 3590 & 76.1 & 1530 & 70.7 & 2060 & 80.6 \\
\hline & No & 1113 & 23.6 & 629 & 29.1 & 484 & 18.9 \\
\hline & NA & 17 & 0.4 & 6 & 0.2 & 11 & 0.5 \\
\hline \multirow{2}{*}{$\begin{array}{l}\text { Reported injuries occurred while } \\
\text { running in past two years* }\end{array}$} & Yes & 2315 & 49 & 1109 & 51.2 & 1206 & 47.2 \\
\hline & No & 2405 & 51 & 1056 & 48.8 & 1349 & 52.8 \\
\hline
\end{tabular}


Table 3: Lifetime diagnoses of chronic conditions reported by recreational runners.

\begin{tabular}{|c|c|c|c|c|c|c|}
\hline \multirow[t]{2}{*}{ Chronic conditions } & \multicolumn{2}{|c|}{ All runners $(N=4720)$} & \multicolumn{2}{|c|}{ Male runners $(N=2165)$} & \multicolumn{2}{|c|}{ Female runners ( $N=2555)$} \\
\hline & $n$ & $\%$ & $n$ & $\%$ & $n$ & $\%$ \\
\hline Depression $^{\star \star}$ & 724 & 15.3 & 240 & 11.1 & 484 & 18.9 \\
\hline Respiratory conditions ${ }^{\star *}$ & 554 & 11.7 & 221 & 10.2 & 333 & 13.0 \\
\hline Anaemia $^{\star \star}$ & 472 & 10.0 & 34 & 1.6 & 438 & 17.1 \\
\hline Hypertension ${ }^{\star \star}$ & 290 & 6.1 & 168 & 7.8 & 122 & 4.8 \\
\hline Skin disease* & 277 & 5.9 & 111 & 5.1 & 166 & 6.5 \\
\hline Cancer & 238 & 5.0 & 108 & 5.0 & 130 & 5.1 \\
\hline Insomnia** & 193 & 4.1 & 54 & 2.5 & 139 & 5.4 \\
\hline Osteoarthritis & 184 & 3.9 & 74 & 3.4 & 110 & 4.3 \\
\hline Gastrointestinal disease ${ }^{\star \star}$ & 186 & 3.9 & 56 & 2.6 & 130 & 5.1 \\
\hline Cardiac conditions & 179 & 3.8 & 94 & 4.3 & 85 & 3.3 \\
\hline Thyroid disease ${ }^{\star \star}$ & 180 & 3.8 & 30 & 1.4 & 150 & 5.9 \\
\hline Neurological conditions & 88 & 1.9 & 37 & 1.7 & 51 & 2.0 \\
\hline Diabetes & 68 & 1.4 & 30 & 1.4 & 38 & 1.5 \\
\hline Rheumatoid arthritis & 54 & 1.1 & 19 & 0.9 & 35 & 1.4 \\
\hline Osteoporosis* & 53 & 1.1 & 14 & 0.6 & 39 & 1.5 \\
\hline Chronic renal failure & 11 & 0.2 & 7 & 0.3 & 4 & 0.2 \\
\hline Cerebral palsy & 8 & 0.2 & 5 & 0.2 & 3 & 0.1 \\
\hline Cystic fibrosis & 7 & 0.1 & 5 & 0.2 & 2 & 0.1 \\
\hline
\end{tabular}

* - statistically significant difference between males and females $(p<0.05)$

$* *$ _ statistically significant difference between males and females $(p<0.001)$.

Table 4: Frequencies of body mass index categories.

\begin{tabular}{|c|c|c|c|c|c|c|}
\hline \multirow[t]{2}{*}{ Body Mass Index } & \multicolumn{2}{|c|}{$\begin{array}{r}\text { All runners } \\
(N=4720)\end{array}$} & \multicolumn{2}{|c|}{$\begin{array}{r}\text { Male runners } \\
(N=2165)\end{array}$} & \multicolumn{2}{|c|}{$\begin{array}{r}\text { Female runners } \\
(N=2555)\end{array}$} \\
\hline & $N$ & $\%$ & $n$ & $\%$ & $n$ & $\%$ \\
\hline Underweight $\left(<18.5 \mathrm{~kg} / \mathrm{m}^{2}\right)^{*}$ & 121 & 2.6 & 17 & 0.8 & 104 & 4.1 \\
\hline Normal $\left(18.5 \text { to }<25 \mathrm{~kg} / \mathrm{m}^{2}\right)^{*}$ & 3443 & 72.9 & 1455 & 67.2 & 1988 & 77.8 \\
\hline Overweight $\left(25 \text { to }<30 \mathrm{~kg} / \mathrm{m}^{2}\right)^{*}$ & 1029 & 21.8 & 637 & 29.4 & 392 & 15.3 \\
\hline Obese $\left(\geq 30 \mathrm{~kg} / \mathrm{m}^{2}\right)$ & 127 & 2.7 & 56 & 2.6 & 71 & 2.8 \\
\hline
\end{tabular}


Table 5: Multiple logistic regression analysis results with adjusted odds ratio (OR) estimates for the effects of runner characteristics on clinically significant weight loss ( $\geq 5 \mathrm{~kg})$.

\begin{tabular}{|c|c|c|c|}
\hline Variable & $\mathrm{OR}^{1}$ & $95 \% \mathrm{Cl}$ & $P$ value \\
\hline \multicolumn{4}{|l|}{ Sex } \\
\hline Female $^{2}$ & 1.00 & & \\
\hline Male & 1.04 & $0.90,1.19$ & 0.62 \\
\hline \multicolumn{4}{|l|}{ Age group } \\
\hline$>55$ years $^{2}$ & 1.00 & & \\
\hline $35-55$ years & 1.91 & $1.43,2.54$ & $<0.001$ \\
\hline$<35$ years & 2.20 & $1.62,2.96$ & $<0.001$ \\
\hline \multicolumn{4}{|l|}{ BMI group } \\
\hline Normal $^{2}$ & 1.00 & & \\
\hline Underweight & 0.69 & $0.42,1.13$ & 0.14 \\
\hline Overweight & 1.96 & $1.68,2.29$ & $<0.001$ \\
\hline Obese & 2.51 & $1.76,3.58$ & $<0.001$ \\
\hline \multicolumn{4}{|c|}{ Running experience } \\
\hline$\geq 10$ years $^{2}$ & 1.00 & & \\
\hline $6-9$ years & 1.22 & $0.98,1.52$ & 0.07 \\
\hline $3-5$ years & 1.63 & $1.36,1.94$ & $<0.001$ \\
\hline$\leq 2$ years & 3.15 & $2.63,3.78$ & $<0.001$ \\
\hline \multicolumn{4}{|c|}{ Participation in other sports } \\
\hline $\mathrm{No}^{2}$ & 1.00 & & \\
\hline Yes & 0.99 & $0.85,1.16$ & 0.92 \\
\hline \multicolumn{4}{|c|}{ Injury occurrence } \\
\hline $\mathrm{No}^{2}$ & 1.00 & & \\
\hline Yes & 1.02 & $0.89,1.69$ & 0.77 \\
\hline
\end{tabular}

\section{Smoking history}

392 Figure 1. Comparison of BMI group percentages between Australian surveyed male (Figure 1a) and 393 female (Figure 1b) runners and Australian population surveyed by Australian Bureau of Statistics of different age groups. 
A Health \& Training Profile of Australian Runners

395 